\title{
Stakeholder Engagement in Maritime Spatial Planning: The Efficacy of a Serious Game Approach
}

\author{
Xander Keijser ${ }^{1,2, *}$, Malena Ripken ${ }^{3}$, Igor Mayer ${ }^{4}$ (D), Harald Warmelink ${ }^{4}$, Lodewijk Abspoel $^{5}$, \\ Rhona Fairgrieve ${ }^{6}$ and Crawford Paris ${ }^{7}$ \\ 1 Environmental Policy Group, Wageningen University, Hollandseweg 1, 6706 KN Wageningen, \\ The Netherlands \\ 2 Rijkswaterstaat, Zuiderwagenplein 2, 8224 AD, Lelystad, P.O. Box 2232, 3500 GE Utrecht, The Netherlands \\ 3 COAST - Centre for Environment and Sustainability Research, Carl von Ossietzky University of Oldenburg, \\ P.O. Box 2503, 26111 Oldenburg, Germany; malena.ripken@uni-oldenburg.de \\ 4 Breda University of Applied Sciences, Academy for Digital Entertainment, Monseigneur Hopmansstraat 1, \\ 4817 JT Breda, The Netherlands; i.s.mayer@hotmail.com (I.M.); warmelink.h@nhtv.nl (H.W.) \\ 5 Ministry of Infrastructure and Water Management, Rijnstraat 8, 2515 XP The Hague, P.O. Box 2090, \\ 2500 EX The Hague, The Netherlands; lodewijk.abspoel@minienm.nl \\ 6 Scottish Coastal Forum, Area 1-A South, Victoria Quay, Edinburgh EH6 6QQ, UK; rhona.fairgrieve@gov.scot \\ 7 School of Geosciences, University of Edinburgh, Drummond Street, Edinburgh EH8 9XP, UK; \\ c.paris@ed.ac.uk \\ * Correspondence: xander.keijser@rws.nl
}

Received: 6 May 2018; Accepted: 29 May 2018; Published: 2 June 2018

\begin{abstract}
The 2014 EU Directive on Maritime Spatial Planning (MSP) lays down obligations for the EU Member States to establish a maritime planning process, resulting in a maritime spatial plan by 2020. Consultation should be carried out with local, national and transnational stakeholders. Stakeholder engagement in MSP is complex because of the great number and diversity of maritime stakeholders and the unfamiliarity of some of these stakeholders with MSP and its potential impact. To facilitate stakeholder engagement in MSP, the 'MSP Challenge' table top strategy game was designed and played as part of several stakeholder events in different European countries. The authors study the efficacy of the game for stakeholder engagement. Background and evaluation data of nineteen game sessions with a total of 310 stakeholders with different backgrounds were collected through post-game surveys. Furthermore, the efficacy of the game for stakeholder engagement processes, organised by competent MSP authorities in Scotland and Belgium, is studied in more detail. The results show that the board game, overall, has been a very efficient and effective way of familiarising a great diversity of stakeholders with MSP and to create meaningful interaction and learning among stakeholders in formal planning processes. However, the case studies also show that contextual factors-the level of familiarity with MSP and participants' perception to sustainability-influences the efficacy of the game.
\end{abstract}

Keywords: Maritime Spatial Planning (MSP); stakeholder participation; serious game; Blue Growth; Good Environmental Status

\section{Introduction}

The diversity and intensity of human activities at sea are staggering. This is due to the rich ecosystem services and resources that are provided by the sea, combined with rapid technological innovation and economic globalization [1,2]. Human activities at sea involve, but are not exclusively reserved to, traditional maritime sectors such as shipping, fishing, dredging, recreation and mineral 
extraction (oil and gas) along with emerging economic sectors such as blue energy (offshore wind, tidal, wave), aquaculture (fish farming) and blue biotechnology [3].

Maritime sectors are increasingly getting into each other's way, not only within an Exclusive Economic Zone (EEZ) but also at a sea basin level, i.e., across borders. The ambitions of one country for offshore wind energy, can easily become the problem of another sector, such as fishing, in a nearby country [4]. National economic interests are at stake. Linear infrastructures—such as cables, pipelines, shipping routes-are transboundary by definition [5]. Sectoral interests and ambitions are voiced by maritime stakeholders, who form intricate webs of actor-networks in countries around a sea basin and try to influence policies at all administrative levels $[3,6]$. The spatial allocation of maritime activities, therefore, has to be coordinated effectively among the countries that share a sea basin $[1,7]$.

An important constraint to the ambitions of maritime sectors and countries is the health status of marine ecosystems. Globally, marine and coastal ecosystems are under enormous pressure $[3,8]$. Human uses are having a cumulative effect on ecosystems that is not yet fully known. Different international treaties and agreements, such as the Convention on Biological Diversity (CBD), including the Aichi targets [9], and the United Nations' Sustainable Development Goal (SDG) 14 call upon nations and stakeholders to 'conserve and sustainably use the oceans, seas and marine resources for sustainable development' [10]. The European Union (EU) adopted the European Marine Strategy Framework Directive (MSFD) which aims to achieve clean, healthy and productive seas (e.g., Good Environment Status) [11]. The Integrated Maritime Policy [12,13] aims to find a balance between Blue Growth (BG) and Good Environmental Status (GES) by using, among other methods, Maritime Spatial Planning.

\subsection{Maritime Spatial Planning}

In 2014, the EU Parliament and Member States agreed on the Maritime Spatial Planning (MSP) Directive (2014/89/EU) [14]. In short, this Directive lays down obligations for the EU Member States to establish a 'maritime planning process', resulting in a 'maritime spatial plan, or plans' (Art 9.) by 2020. MSP is defined as 'a process by which the relevant Member State's authorities analyse and organise human activities in marine areas to achieve ecological, economic and social objectives [14]'. Some key principles underpinning the EU MSP Directive (2014/89/EU) [14] are:

- Integrated planning of all spatial uses and possible conflicts.

- Evidence-based i.e., guided by best available knowledge.

- Ecosystem-based e.g., taking into account monitoring of the cumulative impact of human activities on the ecology.

- Transboundary consultation and co-ordination at sea basin level.

- Information of the general public and consultation of all relevant stakeholders.

At the time of writing, EU Member States are in different implementation stages of the MSP directive. Some countries, such as Denmark, are in the first planning cycle, while other countries have recently implemented a Maritime Spatial Plan or already started a second or third iteration after a review process has been completed $[15,16]$. This makes transnational cooperation even more challenging as countries need to reconcile differences in approaches, mandates and capacity. In light of the above, the EU is actively supporting transboundary co-ordination and stakeholder consultation in the Baltic, Mediterranean, Celtic Seas and North Sea regions, amongst others, via projects supported by European funding mechanisms see [17] for an overview of these projects.

\subsection{Stakeholder Engagement}

Stakeholder engagement, or public participation in relation to policy-making and implementation, is required by both national legislation and international resolutions, such as the Aarhus Convention 1998 [18]. Furthermore, art. 9 of the MSP Directive [14] states: "Member States shall establish means of public participation by informing all interested parties and by consulting the relevant stakeholders 
and authorities, and the public concerned, at an early stage in the development of maritime spatial plans, in accordance with relevant provisions established in Union legislation".

Stakeholder engagement and involvement processes in MSP and other areas is relatively well studied in the academic literature [19]. There are specific handbooks and guidelines about MSP and stakeholder engagement [20], best practices examples from transnational projects [19] and more critical literature on, for instance, stakeholder empowerment [21,22] and inclusivity [23]. In the context of MSP, stakeholders have been defined as 'individuals, groups or organizations who are, in one way or another, interested, involved or affected (positively or negatively) by a particular project or action toward resources' [21]. Requirements for effective stakeholder participation are, among others: willingness and motivation of stakeholders to participate [24]; inclusivity of all possible interests [25]; equal access to information and knowledge [24,26]; timeliness of participation [19,20,23]; safety and fairness in the process [24]. However, studies of (regional) experiences have demonstrated that there are many barriers to effective stakeholder involvement in MSP [19], including the following non-exclusive list of factors that play a role:

- Stakeholder involvement in MSP often means tokenistic participation or cosmetic engagement in a very early stage of the planning process or at the end of process, whereas stakeholders should be 'on board' during the whole planning process [20,21,23,26].

- Not all stakeholders are familiar with MSP, so they are unaware of its possible impact. The sense of urgency among specific type of stakeholders can be low.

- MSP stakeholders include often other States, or government bodies or agencies therein [27].

- Stakeholders have great diversity in terms of capacity and areas of interest: compare national-scale oil and gas companies, offshore wind industry and fishing industries with wreck and recreational divers, recreationists, local fishing communities or indigenous tribes [24,26,28].

- Maritime communities-local fishermen, shippers-have deeply rooted value and belief systems and often reason and talk from 'tacit knowledge', a form of experiential and everyday understanding about the ocean.

- Trust levels in maritime sectors-e.g., local (fishing) communities—have often been adversely affected by previous negative participation experiences and/or political decisions (e.g., discussion on pulse fishing, discard ban) [4].

Because of the great number and diversity of maritime stakeholders in a transboundary context with high and (potentially) conflicting interests, combined with a significant unfamiliarity of these stakeholders with MSP and its potential impacts, stakeholder engagement in MSP is as important as it can be difficult. Several authors have called for innovative approaches and tools for stakeholder involvement in MSP [29]. They should be effective to help identify and reach out to new stakeholders; engage stakeholders; stimulate them to participate; increase the general level of understanding on MSP; create a level playing field; build a common language; give a sense of safety and openness [30]. Personal experience and interactive practice in MSP is essential, as planning can hardly be taught and learned individually or by books [31].

\subsection{Serious Gaming}

Collaborative tools, such as serious game/simulation games (SG) can be used to facilitate stakeholder engagement, to provide opportunities to deepen mutual understanding and to explore and integrate new ideas and solutions. 'Serious games' make use of the technologies of games and the principles of play to achieve objectives that are valued not for their intrinsic value-i.e., merely for the sake of entertainment-but for the extrinsic value achieved by the consequences, such as the fact that engagement and feedback in play is a good condition for learning and change [32].

Since 2011, the authors have been developing and using serious games to support MSP in various ways for education, social learning, stakeholder engagement and decision-support [33]. At the time of writing, the MSP Challenge brand - a not for profit initiative-holds several types of serious games; 
a role-playing game, advanced digital games, a table top strategy board game and a playful discussion method called the Living Q. The MSP Challenge board game has been designed to let stakeholders experience some of the dynamic and complex interactions in ecosystem-based MSP and to start 'thinking and talking' about the interrelations among different marine uses and objectives [34,35].

\subsection{Research Problem}

The aim of this paper is to study the efficacy — the ability in reaching its designed objectives—of the MSP Challenge board game for stakeholder engagement in various planning contexts. We use the following indicators to measure efficacy: the reported perception of learning about MSP, players' satisfaction ratings and the uptake of the game in the MSP community. The main research questions are:

- How and to what extent does playing the MSP Challenge board game raise stakeholder's understanding of MSP?

- How and to what extent do different types of stakeholders enjoy playing the MSP challenge board game?

- How and to what extent do background factors - age, gender, prior level of MSP involvement, sector affiliation and sustainability perception-affect the engagement and learning of stakeholders?

- What are the insights for real world MSP from stakeholder interactions in the game?

\section{Materials and Methods}

\subsection{The MSP Challenge Board Game}

At the end of 2015, the MSP Challenge board game Short Sea Shipping edition, was developed. It was first played in Amsterdam in February 2016 with around 30 stakeholders at a high-level meeting on Short Sea Shipping as part of The Netherlands' EU Presidency [34]. The idea behind the board game was to communicate in an engaging manner the emerging concepts of ecosystem-based MSP, the European Blue Growth Agenda (BG), and Good Environmental Status (GES) to the Short Sea Shipping community $[34,35]$. The simplicity of the game made it a powerful tool for engaging a wider range and greater diversity of people.

Since 2016, several revised editions-with translations into other languages, customisation of icons and symbols and adaptation of planning scales-have been made. The MSP Challenge: Scottish Marine Region edition has been developed to consider transboundary marine planning issues at a sub-national level [36], while the MSP Challenge: Blue Development edition widened the focus from shipping to other economic sectors [37]. At the time of writing, the MSP Challenge board game has been played in twenty countries with hundreds of people in the global MSP community (for an overview of the sessions, see Table 1). Dozens of institutions have been involved in its further development and dissemination.

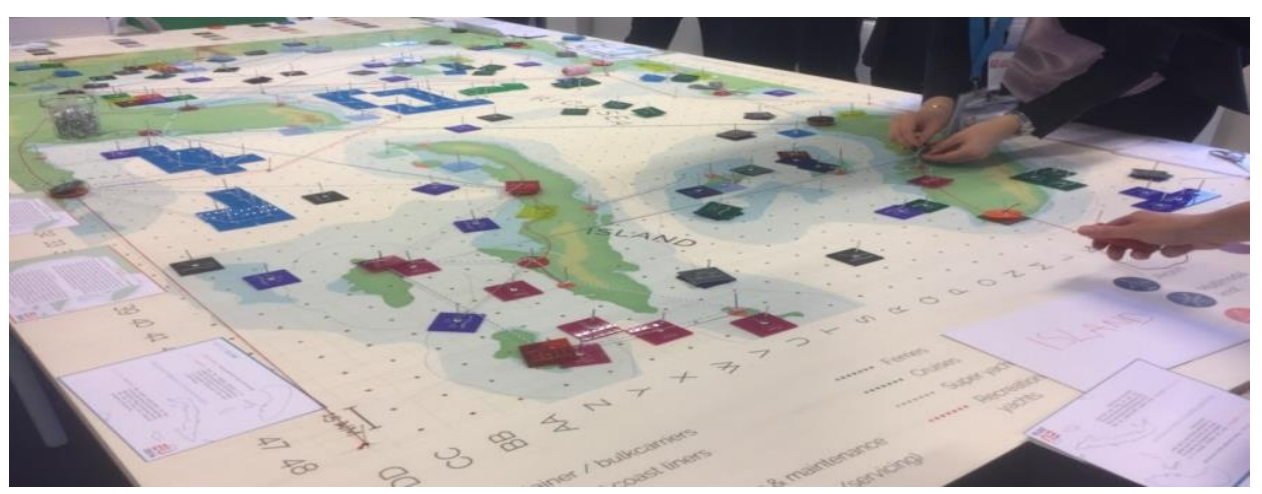

Figure 1. Impression of the MSP Challenge board game. 
Table 1. Overview of MSP Challenge sessions.

\begin{tabular}{|c|c|c|c|c|c|c|c|}
\hline $\begin{array}{l}\text { No. of } \\
\text { Events }\end{array}$ & Name & $\begin{array}{c}\text { No. of } \\
\text { Sessions } \\
\end{array}$ & Date & Duration & No. of Part. & $\begin{array}{l}\text { No. of } \\
\text { Resp. }\end{array}$ & Context \\
\hline 1 & High level meeting on Short Sea Shipping; Amsterdam, The Netherlands & 2 & 15 February 2016 & $1.5 \mathrm{~h}$ & Circa 30 & N.a. & Generic \\
\hline 2 & 20th anniversary event of Scottish Coastal Forum; Edinburgh, Scotland & 2 & 10 March 2016 & $1.5 \mathrm{~h}$ & Circa $40-50$ & N.a. & Generic \\
\hline 3 & NorthSEE kick-of meeting; Hamburg, Germany & 1 & 4 April 2016 & $1.5 \mathrm{~h}$ & Circa 20 & N.a. & Generic \\
\hline 4 & World Maritime University; Malmö, Sweden & 1 & 13 July 2016 & $3 \mathrm{~h}$ & Circa 11 & N.a. & Generic \\
\hline 5 & 3rd Atlantic Stakeholder platform conference; Dublin, Ireland & 1 & 26 September 2016 & $1 \mathrm{~h}$ & Circa 50-60 & 32 & Generic \\
\hline 6 & North Sea Days Conference; Scheveningen, The Netherlands & 1 & 6 October 2016 & $1 \mathrm{~h}$ & Circa 35 & 22 & Generic \\
\hline 7 & Scottish Coastal Forum; Millport, Scotland & 1 & 15 October 2016 & $3 \mathrm{~h}$ & 9 & 9 & Generic \\
\hline 8 & 2nd Baltic MSP Forum; Riga, Latvia & 1 & 24 November 2016 & $1 \mathrm{~h}$ & Circa 35 & 13 & Generic \\
\hline 9 & Van Hall Larenstein; Leeuwarden, The Netherlands & 1 & 12 January 2017 & $2 \mathrm{~h}$ & Circa 25 & N.a. & Generic \\
\hline 10 & Stakeholder start event Belgian MSP; Bruges, Belgium & 5 & 8 February 2017 & $1 \mathrm{~h}$ & Circa 150 & 89 & MSP process \\
\hline 11 & Seas at Risk; Brussels, Belgium & 1 & 21 February 2017 & $1.5 \mathrm{~h}$ & Circa 15 & N.a. & Generic \\
\hline 12 & Kick start Erasmus+ strategic partnership; Liverpool, UK. & 1 & 23 February 2017 & $1.5 \mathrm{~h}$ & Circa 15 & N.a. & Generic \\
\hline 13 & MapSIS Conference; Las Palmas, Gran Canaria & 2 & 27/28 April 2017 & $75 \mathrm{~min}$. & Circa 35 & 31 & Generic \\
\hline 14 & 2nd International Conference on MSP; Paris, France & 1 & 14 March 2017 & $1 \mathrm{~h}$ & Circa 20 & N.a. & Generic \\
\hline 15 & EUSBSR Forum; Berlin, Germany & 1 & 13 June 2017 & $1 \mathrm{~h}$ & Circa 10 & 6 & Generic \\
\hline 16 & Memorial's Master of Marine Studies; St Johns, Canada & 1 & 15 June 2017 & $1.5 \mathrm{~h}$ & Circa 20 & N.a. & Generic \\
\hline 17 & Riverside Museum, Glasgow, Scotland & 1 & 4 July 2017 & $1.5 \mathrm{~h}$ & 7 & 7 & MSP process \\
\hline 18 & Arran High School, Lamlash, Scotland & 1 & 5 July 2017 & $1.5 \mathrm{~h}$ & 10 & 10 & MSP process \\
\hline 19 & MARE Conference; Amsterdam, The Netherlands & 1 & 6 July 2017 & $1.5 \mathrm{~h}$ & Circa 15 & 14 & Generic \\
\hline 20 & Royal West of Scotland Amateur Boat Club, Greenock, Scotland & 1 & 7 July 2017 & $1.5 \mathrm{~h}$ & 19 & 19 & MSP process \\
\hline 21 & Blue Growth Summer School; Ostend, Belgium & 1 & 21 September 2017 & $2 \mathrm{~h}$. & Circa 25 & 21 & Generic \\
\hline 22 & ArtReefs workshop; Varna, Bulgaria & 1 & 10 October 2017 & $1.5 \mathrm{~h}$ & Circa 25 & 11 & Generic \\
\hline 23 & SimCelt closing conference; Liverpool, UK & 1 & 28 November 2017 & 1.5 & Circa 15 & N.a. & Generic \\
\hline \multirow[t]{2}{*}{24} & Van Hall Larenstein; Leeuwarden, The Netherlands & 1 & 30 November 2017 & $2 \mathrm{~h}$ & 26 & 26 & Generic \\
\hline & Total & 32 & N.a. & N.a. & Circa 650 & 310 & N.a. \\
\hline
\end{tabular}


The Maritime Spatial Planning Challenge board game is a table top strategy game, based on a constructionist learning philosophy [38], which suggests that players learn about the world and their relation to it, through creation and construction. The game was originally developed in a period of three months with a small development team consisting of game developers, designers and MSP experts. It has been designed to run for one to three hours, depending on the setting, and involve 12 to 30 players. The game is played on a $2.8 \times 1.6 \mathrm{~m}$ plywood game board, printed with a map of a fictional sea, showing a grid with holes drilled through the middle of each square (See Figure 1). The fictional sea, the 'RICA Sea' is shared by three countries: Bayland, Peninsuland and Island'; each having their own country profile and objectives about the future development of the RICA Sea. At the start of the game, players stand around the board and a simple narrative introduces them to the game: 'Jointly develop the RICA Sea so that at the end of the game, you and others feel comfortable with the state of the RICA Sea and how you developed it'. Players are assigned different roles-maritime spatial planners, nature conservationists or a representative of a marine-related industry-in one of the three countries. Players can develop the RICA Sea by placing various tokens and threads on the game board. Many colourful acrylate squares (i.e., the tokens), with various symbols representing marine environment and human activities, are designed to fit onto the grid in order to build up the picture of ecosystem services and human activities above, on and below the sea surface. Different colours of threads indicate forms of linear infrastructure (e.g., cables, pipelines) and shipping lanes relating to various types of vessels. During the game, the players may gradually find out that they get into each other's way and this should start players 'thinking and talking' about the interrelations among the different activities and objectives. At chosen intervals during the game and at the end of the game, the Moderator, together with the Game Overall Director (G.O.D.), facilitates a discussion with the players, asking questions like 'How did it go?', 'What happened and why?' and 'How does this resemble real life?'. The G.O.D. is an MSP policy expert and he/she has the authority to give additional information, decide on, or intervene in, all matters that are unclear or on situations that arise out of the game scenario. Rules of the game can be tailored to session objectives or invented on the spot to give the gameplay a certain twist. The board game is designed to be an impressionistic, fast and hectic, even chaotic experience; much like reality. Over everything, however, it is intended to be fun. For a more details, see www.mspchallenge.info.

\subsection{Study Design}

\subsubsection{Questionnaires}

Background and evaluation data of nineteen game sessions have been analysed for this study. A questionnaire, based on an evaluation framework [39], was developed to capture participants' feedback. It uses validated questions and constructs for game evaluation to elicit information on demographics, sector of employment, pre-existing MSP involvement, game play experience and appreciation and understanding of Maritime Spatial Planning. The survey is based on self-reporting, with answer categories ranging from 'strongly agree' (5) to 'strongly disagree (1)'. Respondents can also write down a short comment.

A total of 310 stakeholders filled in a post-game survey. The questionnaire is intentionally brief to ensure maximum cooperation. Not all game sessions have been surveyed as the questionnaire was not developed until after success of the game became apparent. Table 1 details the sessions where questionnaires were deployed and the context of the game play.

\subsubsection{Observations}

The majority of game sessions were moderated by the development team with considerable involvement of the different organising hosts. All but two of the sessions in Scotland were moderated by the organising authority only, without involvement of the original developers. Moderators noted down observations for many game sessions. On a few occasions, participants were interviewed on 
camera to capture useful footage for promoting the game and short time lapse videos were made for a couple of sessions to demonstrate how the players developed their maritime world [40]. All sessions had intermediate and post-game reflective discussions to transfer MSP related knowledge and stories and to stimulate and capture learning. The case study in Scotland was systematically observed as part of a Master of Science thesis [41] and the results of the recorded observations illustrate and sustain the conclusions noted here.

\subsubsection{Sessions}

The game sessions differed in terms of duration, number and experience of participants and context. Generic sessions typically took place-with stakeholders or students-as part of an event, such as a conference, a workshop, or learning sessions (e.g., a MSP summer school). These generic game sessions varied from one to three hours and their objectives were to create more attention, awareness and understanding of MSP. Two other types of sessions, identified as 'Belgium' and 'Scotland' were organised by the relevant competent authority to kick start a formal MSP process with stakeholders. These sessions were between $90 \mathrm{~min}$ and $2 \mathrm{~h}$ and are more comparable with each other, allowing analysis in more detail. Table 2 gives a short overview of the session characteristics.

Table 2. MSP Challenge board game sessions—context and characteristics.

\begin{tabular}{|c|c|c|c|}
\hline & Generic & Belgium & Scotland \\
\hline Host organisation & $\begin{array}{l}\text { Conferences, workshops, } \\
\text { education }\end{array}$ & $\begin{array}{l}\text { Belgium Federal } \\
\text { government }\end{array}$ & $\begin{array}{c}\text { Clyde Marine } \\
\text { Planning Partnership }\end{array}$ \\
\hline MSP level & N.a. & National & Regional \\
\hline MSP phase & N.a. & $\begin{array}{l}\text { Revision process of } \\
\text { marine plan }\end{array}$ & $\begin{array}{l}\text { Pre-planning } \\
\text { (initial stage) }\end{array}$ \\
\hline Planning area & N.a. & $\begin{array}{l}\text { Belgium North Sea, } \\
\text { Ca } 3500 \text { km² }^{2}\end{array}$ & $\begin{array}{l}\text { Firth of Clyde, } \\
\text { Ca } 3650 \mathrm{~km}^{2}\end{array}$ \\
\hline Type of stakeholders & $\begin{array}{l}\text { Students, experts, } \\
\text { intermediaries. }\end{array}$ & Sector stakeholders & $\begin{array}{l}\text { Recreational } \\
\text { stakeholders }\end{array}$ \\
\hline Number of respondents & 185 & 89 & 36 \\
\hline MSP Challenge Edition & Various & $\begin{array}{l}\text { Blue Development } \\
\text { Edition }\end{array}$ & $\begin{array}{l}\text { Scottish Marine } \\
\text { Region Edition }\end{array}$ \\
\hline Duration & 1-3 h. per session & $1.5 \mathrm{~h}$. per session & $2 \mathrm{~h}$. per session \\
\hline Nr. of sessions & 11 & 5 & 3 \\
\hline
\end{tabular}

\section{MSP Sessions in Scotland}

In Scotland, the Marine (Scotland) Act 2010 provides the framework for marine spatial planning. This Act requires the creation of a national marine plan and enables the production of regional marine plans under the authority of Scottish Ministers [42]. On 25 March 2015, the Scottish National Marine Plan was adopted. The National Marine Plan will be augmented at the regional level by local Marine Planning Partnerships (MPP), which will develop a suite of regional marine plans in territorial waters (12 nautical miles) [43]. The Clyde Marine Planning Partnership (CMPP) is the first of eleven regional partnerships in Scotland that have been delegated the task to prepare a statutory policy document for the Clyde Marine Region and, as part of the process, will implement a series of consultation sessions with local marine stakeholders over a period of three years [41].

In Scotland, the CMPP organised three separate sessions with the MSP Challenge board game in the summer of 2017. The purpose of these sessions was to develop a dialogue between policy experts and target marine users about the complexities of MSP issues. A special Scottish Marine Region edition of the MSP board game was created for the purpose, overseen by the Scottish Coastal 
Forum and the development team, and supported under the auspices of the EU-funded SIMCelt initiative, which was testing novel ways of stakeholder engagement to facilitate cross-border and transboundary marine planning. These sessions were held to encourage engagement from sectors that had been under-represented in marine planning in the Clyde area up until that point, including a group of stakeholders from the marine recreational sector (coastal rowers, divers, kayakers and coastal swimmers) [41].

\section{MSP Sessions in Belgium}

The first legally binding Marine Spatial Plan for the Belgian Part of the North Sea was approved by Royal Decree in March 2014 [44]. The plan needs to be revised at least every six years. In the spring of 2017, the Ministry for the Environment started with the revision procedure of the Belgian Maritime Spatial Plan which, under Belgian law, must lead to a new Plan by 2020. For the start of this process, a workshop with all competent authorities and stakeholders was organised on 8 February 2017 in Bruges, Belgium [45]. The purpose of the workshop was to inform the public about the revision procedure and to receive ideas from the participants about the future development of the Belgian part of the North Sea. In an event with circa 150 participants from different maritime sectors including scientists and civil servants, the MSP Challenge: Blue Development edition game was used to kick start this revision procedure [45]. The MSP Challenge development team has facilitated five MSP board game sessions together with MSP experts from Belgium.

\subsubsection{Description of the Data Set}

The players were asked about their background; results are shown in Table 3 . A total of 310 participants of the nineteen game sessions filled in the post-game questionnaires. The male/female distribution of the total respondent group is relatively balanced with a slight overrepresentation of male participants. Persons of all age categories participated, from slightly younger than eighteen to above sixty-five. About forty percent of all respondents are active in the non-profit sector (NGOs, research, education) and about thirty percent in the public sector.

Table 3. Player backgrounds.

\begin{tabular}{|c|c|c|c|c|}
\hline & Generic $(n=185)$ & Belgium $(n=89)$ & Scotland $(n=36)$ & Total $(n=310)$ \\
\hline \multirow{7}{*}{ Age } & 0-18: $0(0 \%)$ & 0-18: $0(0 \%)$ & 0-18: $1(3 \%)$ & 0-18: $1(0 \%)$ \\
\hline & 18-25: $37(20 \%)$ & 18-25: $3(3 \%)$ & 18-25: $1(3 \%)$ & 18-25: $41(13 \%)$ \\
\hline & 25-35: $65(35 \%)$ & 25-35: $14(16 \%)$ & 25-35: $6(17 \%)$ & 25-35: 85 (28\%) \\
\hline & 35-45: 49 (27\%) & $35-45: 23(26 \%)$ & 35-45: $1(3 \%)$ & 35-45: 73 (24\%) \\
\hline & 45-55: $16(9 \%)$ & 45-55: $23(26 \%)$ & 45-55: $11(31 \%)$ & 45-55: $50(16 \%)$ \\
\hline & 55-65: $14(8 \%)$ & 55-65: $18(20 \%)$ & 55-65: $11(31 \%)$ & 55-65: $43(14 \%)$ \\
\hline & $65+: 3(2 \%)$ & $65+: 8(9 \%)$ & $65+: 3(8 \%)$ & $65+: 14(5 \%)$ \\
\hline \multirow{2}{*}{ Male/Female } & Male: 91 (50\%) & Male: 55 (62\%) & Male: 18 (50\%) & Male: 164 (53\%) \\
\hline & Female: $92(50 \%)$ & Female: $34(38 \%)$ & Female: $16(44 \%)$ & Female: $142(46 \%)$ \\
\hline \multirow{5}{*}{ Involvement * } & 1: $70(38 \%)$ & $1: 6(7 \%)$ & 1: $23(82 \%)$ & 1: $99(33 \%)$ \\
\hline & 2: $57(31 \%)$ & $2: 32(36 \%)$ & $2: 2(7 \%)$ & 2: $91(30 \%)$ \\
\hline & 3: $22(12 \%)$ & 3: $27(30 \%)$ & 3: $2(7 \%)$ & 3: $51(17 \%)$ \\
\hline & $4: 16(9 \%)$ & 4: $17(19 \%)$ & 4: $0(0 \%)$ & 4: $33(11 \%)$ \\
\hline & 5: $17(9 \%)$ & $5: 5(6 \%)$ & 5: $1(4 \%)$ & 5: $23(8 \%)$ \\
\hline Public sector & $49(27 \%)$ & $44(51 \%)$ & $9(26 \%)$ & $102(34 \%)$ \\
\hline Private sector & $23(13 \%)$ & $28(32 \%)$ & $16(46 \%)$ & $67(22 \%)$ \\
\hline Non-profit & $104(58 \%)$ & $15(17 \%)$ & $5(14 \%)$ & $124(41 \%)$ \\
\hline
\end{tabular}


Table 3 also shows that the three cases-Generic, Belgium, Scotland-differ significantly in terms of backgrounds. In the Generic case, the players are internationally mixed (country background not presented here) with an equal gender balance. On average, the players in this category tend to be early or mid-career professionals (around 20-35 years of age), with some previous involvement in MSP, mainly in the non-profit sector (education, NGO). Typical players in this category were students or graduates from different countries, young researchers or policy officers, who played the game at an MSP conference or workshop.

In the Belgian case, there are more male players with a moderate to high level of involvement in MSP. On average, they have a higher age and are working in the public sector. The players in the Belgian case are already part of a national MSP actor-network, where many of them have previously been involved in the first national Maritime Spatial Planning process.

In the Scottish case, the players on average come from the private sector and have a higher age. They have hardly any or no pre-involvement or knowledge of MSP. For these local and regional players, it was a first encounter with MSP. The intermediate conclusion is that in the analysis, the significant differences among the case studies, need to be taken into account.

\section{Results}

\subsection{MSP Understanding}

According to the participants, the MSP Challenge board game reflects the challenges in real life MSP accordingly and playing the board game has made respondents, in general, more interested in MSP (see Table 4). Furthermore, the players on average report that they have learned about MSP as a result of playing the game. By and large, and based on a great many player debriefings, and observations, as well as player comments in the survey, we conclude that the game is considered meaningful and insightful.

Table 4. MSP understanding-key descriptives.

\begin{tabular}{|c|c|c|c|c|}
\hline Statement/Mean (Standard dev.) & $\begin{array}{r}\text { Generic } \\
(n=185)\end{array}$ & $\begin{array}{l}\text { Belgium } \\
(n=89)\end{array}$ & $\begin{array}{l}\text { Scotland } \\
(n=36)\end{array}$ & $\begin{array}{c}\text { Total } \\
(n=310)\end{array}$ \\
\hline The issues in the game represent the challenges in MSP & $4.1(0.8)$ & $3.9(0.8)$ & $4.4(0.7)$ & $4.1(0.8)$ \\
\hline I have become more interested in MSP & $3.8(0.9)$ & $3.4(1.1)$ & $4.1(0.7)$ & $3.7(1.0)$ \\
\hline I know better what MSP is & $3.8(1.0)$ & $3.4(1.0)$ & $4.2(0.7)$ & $3.7(1.0)$ \\
\hline I can better imagine the different viewpoints on MSP & $4.0(0.9)$ & $3.6(0.9)$ & $4.2(0.7)$ & $3.9(0.9)$ \\
\hline $\begin{array}{l}\text { I gained more insight into what the important factors in } \\
\text { MSP are and how they (can) influence each other }\end{array}$ & $3.9(0.8)$ & $3.6(0.8)$ & $4.1(0.5)$ & $3.8(0.8)$ \\
\hline $\begin{array}{l}\text { I gained insights on how different planning scales (local, } \\
\text { regional, national, international, etc.) can influence } \\
\text { decisions made }\end{array}$ & $3.7(1.0)$ & $3.6(0.8)$ & N.a. & $3.6(1.0)$ \\
\hline General understanding of MSP * (Cronbach's Alpha $=0.85)$ & $3.9(0.8)$ & $3.5(0.8)$ & $4.2(0.5)$ & $3.8(0.8)$ \\
\hline
\end{tabular}

* General MSP understanding is based upon 3 statements: "I know better what MSP is", "I can better imagine the different viewpoints on MSP", and "I gained more insight into what the important factors in MSP are and how they (can) influence each other".

"It has been [an] interesting game, because you can obtain a global idea about MSP and the conflict resolution between sectors, environmental issue and neighbouring countries."

$$
\text { - (participant of MapSiS session). }
$$

There are marked differences among the three cases. Table 4 shows that the respondents who have played the MSP Challenge board game as part of the Clyde Marine Planning Partnership report a significantly stronger perception of learning about MSP than the respondents who played the game at 
a conference or workshop. Participants who played the game as part of the revision of the Belgian Maritime Spatial Plan reported a learning effect that was not as high as the players in the other cases. This might be explained by the level of pre-existing familiarity with MSP of the players.

"As I was familiar with this topic, the game itself did not help me personally to understand the issue better. I can imagine, however, that the MSP Challenge will be very helpful in providing stakeholders (your average layman) in understanding the complicated task of planning and policy implementation in the coastal area."

-(participant of ArtReefs workshop).

More important than the players' reviews or testimonials are the dialogues between the players on various MSP aspects. All players—students, professionals, novices or proficient planners-struggle with words and symbols during the game. This can be exacerbated as the players come from different countries and cultural backgrounds. Through the gameplay players get to know and understand one another better.

\subsection{Engagement}

Based upon observations of the facilitators, video recordings, and the results of the questionnaires, we can safely conclude that the participants of the MSP Challenge board game sessions get, in general, deeply engaged and immersed in the game. After the short introduction, the players jump into it, and the moderator often has a hard time stopping the players for intermediate or post-game reflections. The following quotes are an illustration of player-stakeholder engagement.

"Really interesting and innovative way [for] getting people to think about the different interests and viewpoints of the various stakeholders."

—(participant of Atlantic Strategy Stakeholder Conference).

"The game shows clearly how governance and communication links work in reality. Everyone undermines the planners and mind[s] their own interest."

$$
\text { - (participant of Baltic MSP forum). }
$$

The players take their role as planners or stakeholder very seriously. They show all kinds of emotions, signs of pleasure, team work as well as argument and conflict. In general, across almost all sessions, the experience is that all stakeholders pursue their own interests and try to realise their ambitions; the Marine Planners have a difficult task getting everyone aligned. The game tends to be hectic and chaotic, but extremely immersive. The half way reflection challenges the players to improve and solve their conflicts through better national, sectoral and transboundary planning in the second part of the game.

Table 5 shows that the participants enjoy playing the game although the responses differ per case, with a very high enjoyment score for Scotland. The respondents strongly recommend the game to others. This is further evidenced by the uptake of the MSP Challenge board game by the MSP community.

Table 5. Gameplay experience-key descriptives.

\begin{tabular}{ccccc}
\hline Statement/Mean (Standard dev.) & $\begin{array}{c}\text { Generic } \\
(\boldsymbol{n}=\mathbf{1 8 5})\end{array}$ & $\begin{array}{c}\text { Belgium } \\
(\boldsymbol{n}=\mathbf{8 9})\end{array}$ & $\begin{array}{c}\text { Scotland } \\
(\boldsymbol{n}=\mathbf{3 6})\end{array}$ & $\begin{array}{c}\text { Total } \\
(\boldsymbol{n}=\mathbf{3 1 0})\end{array}$ \\
\hline I think it is easy to learn how to play the game. & $4.0(0.8)$ & $3.8(0.8)$ & $4.1(0.8)$ & $3.9(0.8)$ \\
I think the information provided in the game is clear. & $3.8(0.8)$ & $3.7(0.8)$ & N.a. & $3.7(0.8)$ \\
I think the game is visually appealing. & $4.6(0.6)$ & $4.2(0.7)$ & N.a. & $4.4(0.6)$ \\
I feel creative while playing the game. & $4.1(0.9)$ & $3.9(0.8)$ & N.a. & $4.0(0.9)$ \\
I think the game is fun. & $4.5(0.6)$ & $4.0(0.9)$ & N.a. & $4.3(0.8)$ \\
I enjoy playing the game. & $4.4(0.7)$ & $4.0(0.9)$ & $4.7(0.6)$ & $4.3(0.8)$ \\
I am likely to recommend this game to others. & $4.2(0.8)$ & $4.0(0.8)$ & $4.4(0.6)$ & $4.2(0.8)$ \\
\hline
\end{tabular}




\subsection{Mediating Factors}

In order to understand better how the game works for different player backgrounds, we examined the possible intermediating effects of age, gender, country of origin, MSP involvement, sector of professional affiliation and sustainability perception, by performing various statistical analysis.

Table 6 gives an overview of the results of the correlation between different background factors (age, gender, level of involvement, sector affiliation) on MSP understanding and gameplay enjoyment, for all sessions and for the three cases separately. The analysis shows that younger players significantly enjoy the gameplay a little more than older players while females seem to enjoy playing the game more than men. There are also significant differences with regard to self-reported learning on MSP. The analysis shows a significant, negative relationship between previous involvement in MSP and self-reported learning. Players who have previously been engaged in MSP seem to pick up less new things from the game. The analysis also shows a significant difference in terms of learning based on the country of origin; with regard to enjoyment this relationship is less strong. Possibly, players with different cultural backgrounds do not respond the same to the gameplay.

Table 6. Correlation results MSP understanding and enjoyment.

\begin{tabular}{cccccc}
\hline & & Generic & Belgium & Scotland & Total \\
\hline 'MSP understanding' vs 'Age' & Spearman's rho (sig) & $-0.11(0.15)$ & $0.04(0.74)$ & $0.18(0.32)$ & $-0.09(0.11)$ \\
\hline 'MSP understanding' vs 'Gender' & Kruskal Wallis sign. & 0.02 & 0.28 & 0.92 & 0.07 \\
\hline 'MSP understanding' vs 'Sector' & Kruskal Wallis sign & 0.03 & 0.05 & 0.92 & 0.87 \\
\hline $\begin{array}{c}\text { MSP understanding' vs } \\
\text { 'MSP involvement' }\end{array}$ & Spearman's rho (sig) & $-0.04(0.56)$ & $-0.23 *(0.03)$ & $-0.05(0.82)$ & $-0.19^{* *}(0.00)$ \\
\hline $\begin{array}{c}\text { 'MSP understanding' vs } \\
\text { 'Country of origin' }\end{array}$ & Kruskal Wallis sign. & 0.00 & N.a. & N.a. & 0.00 \\
\hline $\begin{array}{c}\text { 'MSP understanding' vs } \\
\text { 'Soft sustainability' }\end{array}$ & Spearman's rho (sig) & $0.20^{* *}(0.01)$ & $0.29 * *(0.01)$ & N.a. & $0.16^{* *}(0.01)$ \\
\hline $\begin{array}{c}\text { 'MSP understanding' vs } \\
\text { 'Hard sustainability' }\end{array}$ & Spearman's rho (sig) & $0.03(0.70)$ & $-0.02(0.88)$ & N.a. & $0.05(0.44)$ \\
\hline 'Enjoyment' vs 'Age' & Spearman's rho (sig) & $-0.03(0.69)$ & $-0.18(0.09)$ & $-0.26(0.13)$ & $-0.15{ }^{* *}(0.01)$ \\
\hline 'Enjoyment' vs 'Gender' & Kruskal Wallis sign. & 0.00 & 0.59 & 0.82 & 0.00 \\
\hline 'Enjoyment' vs 'Sector' & Kruskal Wallis sign & 0.23 & 0.47 & 0.39 & 0.39 \\
\hline $\begin{array}{c}\text { 'Enjoyment' vs } \\
\text { 'MSP involvement' }\end{array}$ & Spearman's rho (sig) & $0.15 *(0.04)$ & $-0.10(0.36)$ & $0.29(0.15)$ & $-0.03(0.61)$ \\
\hline 'Enjoyment' vs 'Country of origin' & Kruskal Wallis sign. & 0.10 & N.a. & N.a. & 0.00 \\
\hline $\begin{array}{c}\text { 'Enjoyment' vs } \\
\text { 'Soft sustainability' }\end{array}$ & Spearman's rho (sig) & $-0.02(0.80)$ & $-0.05(0.64)$ & N.a. & $-0.08(0.21)$ \\
\hline $\begin{array}{c}\text { 'Enjoyment' vs } \\
\text { 'Hard sustainability' }\end{array}$ & Spearman's rho (sig) & $0.01(0.93)$ & $0.23 *(0.04)$ & N.a. & $0.12 *(0.05)$
\end{tabular}

${ }^{*}$ means result is significant at $0.05 ;{ }^{* *}$ means result is significant at 0.01 , Note: only Spearman's rho results are presented; Kendall's tau analysis showed similar results.

Table 7 provides an overview of the results of respondents with regard to two statements on sustainability ('hard' vs 'soft' sustainability). Hard sustainability indicates an attitude that ecology should be given priority over economic growth. Soft sustainability indicates the attitude that economic growth and sustainability can go hand in hand, for instance through technological innovation. Player-stakeholders from the Belgium group who agree more with the statement that measures 'hard sustainability', significantly report more enjoyment in the game, while player-stakeholders who agree more with the statement measuring 'soft sustainability', report a significantly higher level of self-reported learning (see Table 6). This is an interesting result, although the reasons behind it are largely speculative. It may relate to the level of trust of the participants in whether this game, or a game-based approach in general, is able to address the real problems of MSP. 
Table 7. Sustainability perspective-—key descriptives.

\begin{tabular}{llccc}
\hline \multicolumn{1}{c}{ Statement/Mean (Standard dev.) } & $\begin{array}{c}\text { Generic } \\
(\boldsymbol{n}=\mathbf{1 8 1})\end{array}$ & $\begin{array}{c}\text { Belgium } \\
(\boldsymbol{n}=\mathbf{8 6})\end{array}$ & Scotland & $\begin{array}{c}\text { Total } \\
(\boldsymbol{n}=\mathbf{2 6 7})\end{array}$ \\
\hline $\begin{array}{l}\text { Depletions in natural resources and decline of biodiversity } \\
\text { can be compensated for through economic growth and } \\
\text { improvements in technology (Soft sust. Factor). }\end{array}$ & $2.7(1.3)$ & $3.2(1.1)$ & N.a & $2.9(1.2)$ \\
$\begin{array}{l}\text { Human activity and economic development should not be } \\
\text { allowed to undermine natural systems and processes that } \\
\text { are vital to the existence of humans. (Hard sust. Factor). }\end{array}$ & $4.2(0.9)$ & $3.9(1.0)$ & N.a & $4.1(0.9)$ \\
\hline $\begin{array}{l}\text { Note: Mann-Whitney test shows significance differences in response between the Generic and Belgium case with } \\
\text { regard to soft sustainability statement }(p=0.00) \text { and hard sustainability statement }(p=0.01) .\end{array}$
\end{tabular}

\subsection{Insights and Lessons for Real World MSP}

From the observations of the facilitators during the different MSP Challenge sessions the following insights and lessons can be drawn.

Players engage deeply in discussions about 'the ecosystem-based approach', 'land-sea interaction' or 'cumulative effects'. Participants ask all sorts of questions, such as "What is blue biotech?", "Which functions can be combined (co-exist)? and 'How does one re-route an international shipping lane?" The MSP Challenge board game allows players to make mistakes or act in an inconsistent way, such as planning wind farms in water deeper than $50 \mathrm{~m}$ despite being told not to do so at first. The game uses this as a learning experience and allows for future innovations to change game conditions and introduce new situations that must be taken into account (e.g., floating wind farms that are not restricted to certain water depths).

The MSP Challenge board game also lets players learn about different roles, responsibilities, and limitations. The role of the maritime spatial planner, including their authority and planning instruments, is quite challenging to comprehend and is especially heavily debated. Planners deploy different planning styles as in real life. In the game, most planners try a pro-active, top-down approach, although others plan in reaction to proposed developments and a few are able to plan in an adaptive mode. Real world stakeholders-shippers, fishers, scientists-are often ask to step into the role of the planner to experience first-hand what it means to be a marine spatial planner and consider multiple different interests all at once. Some of them immediately take the lead by nature, while others let themselves be overrun by the stakeholders (e.g., other players). The players also experience the consequences of their decisions through the response of other players in the board game.

Another aspect that plays an important role in the game as well as in real life is resources (e.g., man power, time, tokens). In one session, there was no fisheries representative in a country and, as a result, other stakeholders were putting claims (e.g., tokens of other economic functions) on important fishing grounds without anyone to stop them. The important lesson for the stakeholder-players is that it is important to be 'at the table' and participating actively to avoid finding yourself being served up 'on it'.

The game also brings many realistic conflicts and tensions to the surface. They revolve around the disputed boundaries of an Exclusive Economic Zone, the development of shared energy infrastructure such as an offshore power grid and energy island, and the development of short sea shipping connections, such ferries and cruise lines. Negotiations take place among the stakeholders and planners within the same country, as well as among the three countries. Transnational cooperation, however, is not a given even when players know that they share the RICA Sea with others. The focus of the players is first to develop their own part of the RICA Sea and only afterwards start to think about transnational cooperation. Often, at the end of the session, participants describe the RICA Sea as 'chaotic'. If they could play again, they would do it differently. 
"Nice to see how you experience that you first go for your own interests, then national, and only then international in this game. Actually, it isn't good, but this is how it worked. Also: everyone wants to plan as much as possible."

— (participant of North Sea Days session).

\section{Discussion}

In terms of the MSP stakeholder engagement purpose, indicators for a good efficacy of the board game are: the reported perception of learning about MSP, players' satisfaction ratings and the uptake of the game in the MSP community. Our analysis shows that, in general, all participants enjoyed playing the MSP Challenge board game but that there are differences between the three cases relating to the self-reported perception of learning about MSP and gameplay enjoyment. These differences can be explained by key session characteristics (such as quality of facilitation, duration of the session, number of participants, personality of the participants and group dynamics), but also on key characteristics of the participants (such as age, gender, country of origin, level of involvement and perspective on sustainability).

Each MSP challenge session is as unique as the number and combination of players, the interaction between them, the context of the session and the facilitation of the game by the moderator and G.O.D. The players, together with the facilitators, make the game; the discussions between them and the facilitators on different aspects of MSP are key to the gameplay and learning experience. Although the design of the game is similar across the sessions, different facilitators and the way they run the events might have an influence on the way the players perceive the game and the subsequent reported learning about MSP. Some participants might benefit from greater explanation about their roles or possible interactions between activities, while others prefer a looser gameplay. To what extent these factors play a role is a topic for further research. Based upon our experience and feedback received from the players, it is recommended to play the MSP Challenge board game for 90-120 min with 15 to 21 players. Experience has shown that sessions with fewer players might miss out on interesting discussions as some stakeholder roles are not being played. More than 7 players per country makes the gameplay more chaotic, which might influence transnational cooperation as planners and stakeholders have a hard time in realising national objectives.

The MSP Challenge board game works very well as an introductory game (i.e., entry level game) for participants with a limited knowledge of MSP as it provides a build-up of information in an informal manner. From the Scottish case, it became evident that the participants' general lack of previous involvement in MSP did not appear to affect their ability to learn and enjoy playing the game. Instead, it could be argued that selecting and characterising these stakeholders because of their lack of involvement actually enhances learning and knowledge exchange. The interaction in the game among players who are proficient in MSP and those who are novices can of course be very beneficial at a group or team level, where both might learn from each other. The experts, for instance, form the questions and explain things that are unclear to the incumbents and the novices learn from the contributions of the experts. The game is not only an individual learning experience but also a shared social learning experience.

Additionally, sustained debate and enthusiasm for MSP, coupled with a likeliness to recommend the game to others, also hinted at the potential for wider learning within the broader stakeholder community. Participants continuing debates and demonstrating enthusiasm over MSP issues after the MSP Challenge sessions had finished alluded to the potential comparative effectiveness of gaming over more traditional methods of engagement. Although this cannot be decisively concluded here, further studies may wish to examine this comparison, perhaps investigating the extent to which post-workshop knowledge of MSP is demonstrated within broader stakeholder groups after playing a 'serious game' such as the MSP Challenge board game. Future research will focus on the role of advanced (digital) gaming for other forms of stakeholder engagement in the MSP process, such as in 
later stages of the development of Maritime Spatial Plans, for scenario-analysis and for transboundary co-operation among stakeholders and planners.

\section{Conclusions}

We can conclude that, in general, MSP stakeholders from any sector and background can enjoy and appreciate the experience of the Maritime Spatial Planning Challenge board game. Whether participants have a better understanding of MSP after playing the board game depends, amongst others, on key characteristics of the participant's own professional background, notably their country of origin, level of involvement in MSP and their perspective on sustainability.

Author Contributions: The original idea of the MSP Challenge board game is from L.A. The concept of the board game has been further developed by a small team, including the authors L.A., I.M. and X.K. The Scottish Marine Region edition has been developed together with R.F. All authors have moderated and/or facilitated various MSP Challenge board game sessions in which data collection for this paper has taken place. C.P. has analysed the Scottish board game sessions into detail for his master thesis and provided input on the Scottish case study for this paper. The conceptualisation of the paper has been done by I.M., H.W. and X.K. Data analysis has been done by X.K. and H.W. The first drafts of the paper have been written by X.K. with input of M.R. and I.M, I.M. supervised the process. All authors have provided input on different sections of the paper. R.F. and C.P. have performed a final editing and language check.

Acknowledgments: This research is part of the PhD thesis by the first author X.K. on the use of Serious Gaming in (transboundary) Maritime Spatial Planning at Wageningen University, The Netherlands, with support of Rijkswaterstaat. The board game editions have been made possible by the Dutch Ministry of Infrastructure and Water Management, the Scottish Government (Marine Scotland, with financial support from the EU-funded SIMCelt project (www.simcelt.eu), the University of Liverpool in the UK, the Federal Ministry of Transport and Digital Infrastructure in Germany and the University of Oldenburg in Germany. The authors are grateful to Gesine Meissner, chair of the Searica Intergroup European Parliament for giving us permission to use 'RICA Sea' as playground of the board game. The authors thank all other contributors, supporters and players, too many to mention by name.

Conflicts of Interest: The authors declare no conflict of interest.

\section{References}

1. Jay, S.; Alves, F.L.; O'Mahony, C.; Gomez, M.; Rooney, A.; Almodovar, M.; Gee, K.; de Vivero, J.L.S.; Gonçalves, J.M.S.; da Luz Fernandes, M.; et al. Transboundary dimensions of marine spatial planning: Fostering inter-jurisdictional relations and governance. Mar. Policy 2016, 65, 85-96. [CrossRef]

2. Douvere, F.; Ehler, C.N. New perspectives on sea use management: Initial findings from European experience with marine spatial planning. J. Environ. Manag. 2009, 90, 77-88. [CrossRef] [PubMed]

3. Kannen, A. Challenges for marine spatial planning in the context of multiple sea uses, policy arenas and actors based on experiences from the German North Sea. Reg. Environ. Chang. 2014, 14, 2139-2150. [CrossRef]

4. Jentoft, S.; Knol, M. Marine spatial planning: Risk or opportunity for fisheries in the North Sea? Marit. Stud. 2013, 12, 13. [CrossRef]

5. Ehler, C.N.; Douvere, F. An International Perspective on Marine Spatial Planning Initiatives. Environments 2010, 37, 9-20.

6. Weible, C.M. An Advocacy Coalition Framework Approach to Stakeholder Analysis: Understanding the Political Context of California Marine Protected Area Policy. J. Public Admin. Res. Theory 2006, 17, 95-117. [CrossRef]

7. Van Tatenhove, J.P.M. Transboundary marine spatial planning: A reflexive marine governance experiment? J. Environ. Policy Plan. 2017, 7200, 783-794. [CrossRef]

8. Tamis, J.E.; de Vries, P.; Jongbloed, R.H.; Lagerveld, S.; Jak, R.G.; Karman, C.C.; Van der Wal, J.T.; Slijkerman, D.M.; Klok, C. Toward a harmonized approach for environmental assessment of human activities in the marine environment. Integr. Environ. Assess. Manag. 2016, 12, 632-642. [CrossRef] [PubMed]

9. United Nations Convention of Biological Diversity. Available online: https://www.cbd.int/sp/targets/ (accessed on 4 May 2018).

10. United Nations. Transforming Our World: The 2030 Agenda for Sustainable Development; General Assembly Seventieth Session (A/70/L.1); United Nations: New York, NY, USA, 2015; pp. 1-35. 
11. European Union. Directive 2008/56/EC of the European Parliament and of the Council of 17 June 2008 establishing a framework for community action in the field of marine environmental policy (Marine Strategy Framework Directive). Off. J. Eur. Union 2008, L164, 19-40. Available online: http:/ / eur-lex.europa.eu/ LexUriServ /LexUriServ.do?uri=OJ:L:2008:164:0019:0040:EN:PDF (accessed on 4 May 2018).

12. European Union. Communication from the Commission to the European Parliament, the Council, the European Economic and Social Committee and the Committee of the Regions-An Integrated Maritime Policy for the European Union; COM (2007) 574 Final; European Commission (EC): Brussels, Belgium, 2007; Available online: http:/ / eur-lex.europa.eu/legal-content/EN/TXT/PDF/?uri=CELEX:52007DC0575\&from=EN (accessed on 4 May 2018).

13. European Union. European Commission Progress of the EU's Integrated Maritime Policy; COM 46 Final; European Commission: Luxembourg, 2012; p. 15. Available online: https://ec.europa.eu/maritimeaffairs/sites/ maritimeaffairs / files/docs/publications/imp-progress-report_en.pdf (accessed on 4 May 2018).

14. European Union. Directive 2014/89/EU of the European Parliament and of the Council of 23 July 2014 Establishing a Framework for Maritime Spatial Planning. Available online: http:/ / eur-lex.europa.eu/legalcontent/EN/TXT/PDF/?uri=CELEX:32014L0089\&from=EN (accessed on 4 May 2018).

15. Olsen, E.; Fluharty, D.; Hoel, A.H.; Hostens, K.; Maes, F.; Pecceu, E. Integration at the Round Table: Marine Spatial Planning in Multi-Stakeholder Settings. PLoS ONE 2014, 9, e109964. [CrossRef] [PubMed]

16. The United Nations Educational, Scientific and Cultural Organisation (UNESCO). MSP around the World. Available online: http:/ / msp.ioc-unesco.org/world-applications/overview / (accessed on 4 May 2018).

17. European Union. Maritime Affairs Maritime Spatial Planning. Available online: https://ec.europa.eu/ maritimeaffairs/policy/maritime_spatial_planning_en (accessed on 4 May 2018).

18. United Nations Economic Commission for Europe Convention on Access to Information, Public Participation in Decision-Making and Access to Justice in Environmental Matters. Aarhus Convention, 25 June 1998. Available online: http:/ / www.unece.org/fileadmin/DAM/env/pp/documents/cep43e.pdf (accessed on 4 May 2018).

19. Pentz, A.T.-A. BaltSeaPlan Report 24 Stakeholder Involvement in Maritime Spatial Planning; BaltSeaPlan: Hamburg, Germany, 2012; pp. 1-23.

20. Ehler, C.; Douvere, F. Marine Spatial Planning: A Step-by-Step Approach toward Ecosystem-Based Management; Intergovernmental Oceanographic Commission and Man and the Biosphere Programme; IOC Manual; UNESCO: Paris, France, 2009; pp. 1-98.

21. Pomeroy, R.; Douvere, F. The engagement of stakeholders in the marine spatial planning process. Mar. Policy 2008, 32, 816-822. [CrossRef]

22. Tafon, R.V. Taking power to sea: Towards a post-structuralist discourse theoretical critique of marine spatial planning. Environ. Plan. C Politics Space 2018, 36, 258-273. [CrossRef]

23. Flannery, W.; Healy, N.; Luna, M. Exclusion and non-participation in Marine Spatial Planning. Mar. Policy 2018, 88, 32-40. [CrossRef]

24. Gunton, T.; Rutherford, M.; Dickinson, M. Stakeholder Analysis in Marine Planning. Environments 2010, 37, 95-110.

25. Reed, M.S. Stakeholder participation for environmental management: A literature review. Biol. Conserv. 2008, 141, 2417-2431. [CrossRef]

26. Gopnik, M.; Fieseler, C.; Cantral, L.; McClellan, K.; Pendleton, L.; Crowder, L. Coming to the table: Early stakeholder engagement in marine spatial planning. Mar. Policy 2012, 36, 1139-1149. [CrossRef]

27. Smith, G.; Jentoft, S. Marine spatial planning in Scotland. Levelling the playing field? Mar. Policy 2017, 84, 33-41. [CrossRef]

28. Fletcher, S.; McKinley, E.; Buchan, K.C.; Smith, N.; McHugh, K. Effective practice in marine spatial planning: A participatory evaluation of experience in Southern England. Mar. Policy 2013, 39, 341-348. [CrossRef]

29. Pınarbaşı, K.; Galparsoro, I.; Borja, Á.; Stelzenmüller, V.; Ehler, C.N.; Gimpel, A. Decision support tools in marine spatial planning: Present applications, gaps and future perspectives. Mar. Policy 2017, 83, 83-91. [CrossRef]

30. Gazzola, P.; Onyango, V. Shared values for the marine environment-developing a culture of practice for marine spatial planning. J. Environ. Policy Plan. 2018, 1-14. [CrossRef] 
31. Morf, A.; Perus, J.; Steingrimsson, S.A.; Ekenger, M. Results 2nd Nordic Workshop on MSP-Results of the 2nd Nordic Workshop on Marine Spatial Planning and an Update for 2014-Use and Management of Nordic Marine Areas: Today and Tomorrow; Nordisk Ministerråd: Copenhagen, Denmark, 2014; 96p.

32. Mayer, I.S. Playful Organisations \& Learning Systems; NHTV Breda University of Applied Science: Breda/The Hague, The Netherlands, 2016; ISBN 978-90-825477-0-2.

33. Mayer, I.S.; Zhou, Q.; Abspoel, L.; Keijser, X. Gaming the Future of the Ocean: The Marine Spatial Planning Challenge 2050. In SGDA 2014: Serious Games Development and Applications; LNCS 8778; Springer: Cham, Switserland, 2014; pp. 150-162.

34. Keijser, X.; Ripken, M.; Warmelink, H.; Abspoel, L.; Fairgrieve, R.; Mayer, I.S. Maritime Spatial Planning-A Board Game for Stakeholder Involvement. In ISAGA 2017: Simulation Gaming. Applications for Sustainable Cities and Smart Infrastructures; Springer: Berlin/Heidelberg, Germany; Delft, The Netherlands, 2017.

35. Government of The Netherlands; Breda University of Applied Sciences. Maritime Spatial Planning Challenge: Short Sea Shipping Edition February 2016 Handbook; Government of The Netherlands: The Hague, The Netherlands, 2016.

36. Government of The Netherlands; Breda University of Applied Sciences. Maritime Spatial Planning Challenge: Scottish Marine Region Edition September 2016 Player's Handbook; Government of The Netherlands: The Hague, The Netherlands, 2016.

37. Government of The Netherlands; Breda University of Applied Sciences. Maritime Spatial Planning Challenge: Blue Development Edition January 2017 Handbook; Government of The Netherland: The Hague, The Netherlands, 2017; pp. 1-13.

38. Papert, S.; Harel, I. Constructionism; Ablex Publishing Corporation: Norwood, NJ, USA, 1991.

39. Mayer, I.S.; Bekebrede, G.; Harteveld, C.; Warmelink, H.; Zhou, Q.; van Ruijven, T.; Lo, J.; Kortmann, R.; Wenzler, I. The research and evaluation of serious games: Toward a comprehensive methodology. Br. J. Educ. Technol. 2014, 45, 502-527. [CrossRef]

40. MSP Challenge. Available online: www.mspchallenge.info (accessed on 22 February 2018).

41. Paris, C. Using Serious Games in Regional Marine Planning. An Innovative Stakeholder Engagement Pilot Project in the Clyde Marine Region. Master's Thesis, University of Aberdeen, Aberdeen, UK, 2017.

42. The Scottish Government. Marine (Scotland) Act 2010; 2010 Asp 5; The Scottish Government: Edinburgh, 2010; pp. 1-112. Available online: https://www.legislation.gov.uk/asp/2010/5/pdfs/asp_20100005_en.pdf (accessed on 2 March 2018).

43. The Scottish Government. Scotland's National Marine Plan: A Single Framework for Managing Our Seas; The Scottish Government: Edinburgh, UK, 2015; ISBN 9781785442148.

44. FOD Volksgezondheid, Veiligheid van de Voedselketen en Leefomgeving. Royal Decree Marine Spatial Plan for the Belgian Part of the North Sea. 2014. Available online: https:/ / www.health.belgium.be/sites/default/ files/uploads/fields/fpshealth_theme_file/19094275/Summary\%20Marine\%20Spatial\%20Plan.pdf (accessed on 2 March 2018).

45. FOD Volksgezondheid, Veiligheid van de Voedselketen en Leefomgeving. Available online: https://www. health.belgium.be/nl/news/startschot-herziening-marien-ruimtelijk-plan (accessed on 4 May 2018).

(C) 2018 by the authors. Licensee MDPI, Basel, Switzerland. This article is an open access article distributed under the terms and conditions of the Creative Commons Attribution (CC BY) license (http:// creativecommons.org/licenses/by/4.0/). 